\title{
Alkaline phosphatase in auxiliary liver transplantation
}

\section{J. JERSKY}

From the Department of Surgery, University of the Witwatersrand, Johannesburg, South Africa

SUMMARY Auxiliary liver allografts were inserted into baboons and allowed to undergo rejection. The incorporation of ${ }^{14} \mathrm{C}$ leucine into alkaline phosphatase was measured in both host and donor livers with the aid of an anti-alkaline phosphatase antibody. The results indicate that the increased serum alkaline phosphatase levels found under these circumstances are due to increased synthesis of the enzyme by both livers. Furthermore, it was shown that in the absence of biliary obstruction, this enhanced production of alkaline phosphatase is accompanied by an increase in the excretion of the enzyme into bile. It is suggested that the stimulus for the enhanced production of alkaline phosphatase is a substance which is normally produced in the liver and excreted into the bile.

In recent years it has become clear that the increased serum alkaline phosphatase activity associated with certain hepatobiliary disorders is accompanied by a similar rise in the liver itself. Although this finding is suggestive of hepatic overproduction of the enzyme, other interpretations are possible and have not been formally excluded. For example, the increased activity could be due to an enhanced efficiency of the enzyme as the result of a conformational change in the molecule or of a change in the concentration of various modifier substances. Such objections to the conclusion that the increased activity is due to enhanced synthesis can be overcome by the use of a method of identification which does not depend on the catalytic properties of the enzyme.

In the experiments described in this paper, a specific anti-baboon hepatic alkaline phosphatase antibody was used to isolate the enzyme from serum, bile, and liver extracts obtained from baboons which had previously been injected with ${ }^{14} \mathrm{C}$ leucine. As this amino acid is incorporated into the alkaline phosphatase molecule, the radioactivity in the precipitates provided an index of the rate of formation of the enzyme.

The experimental model chosen was that of auxiliary liver transplantation, as very high levels of serum alkaline phosphatase activity occur in hepatic allograft rejection in baboons (Myburgh, Abrahams, Mendelsohn, Mieny, and Bersohn, 1971). An

Received for publication 30 April 1974. additional advantage of this model, as will be shown, is that increased formation of the enzyme in these circumstances is not confined to the graft, but also occurs in the normal, unobstructed host liver, thus allowing a study to be made of biliary excretion of the enzyme. This has not been possible in previously published experiments, where partial or total obstruction to bile flow has been utilized as the stimulus to produce high serum levels of alkaline phosphatase activity.

\section{Material and Methods}

All the experiments were carried out on healthy Chacma baboons (papio ursinus), each weighing about $12 \mathrm{~kg}$.

\section{INFUSION EXPERIMENTS}

The common bile duct was ligated in a baboon. Subsequently, jaundiced serum from this animal together with $5 \mu \mathrm{Ci}$ of ${ }^{125}$ I-labelled albumin was infused into three healthy baboons. The clearance of alkaline phosphatase, bilirubin, and ${ }^{125}$ I albumin from the serum was then measured over a 72-hour period. In addition, alkaline phosphatase activity in the liver and bile was measured at the beginning of the experiment and after 24,48 , and 72 hours.

AUXILIARY LIVER-TRANSPLANT EXPERIMENTS The net rate of formation of alkaline phosphatase was assessed in normal baboons and in animals into 
which auxiliary livers had been inserted, by measuring the incorporation of ${ }^{14} \mathrm{C}$ leucine into the enzyme in the blood and the liver tissue and gallbladder bile from both host and donor livers 24 hours after an intravenous injection of the isotope $(20 \mu \mathrm{Ci} / \mathrm{kg}$ body weight). In addition, alkaline phosphatase and glutamic-oxaloacetic and pyruvic transaminase activity was measured in these tissues and electrophoretic analysis of the alkaline phosphatase was carried out in starch gel.

\section{Group 1}

Three control animals were subjected to repeated laparotomies under general anaesthesia in order to assess the effect of these procedures on the baseline values of the measured parameters. The first laparotomy was followed by a second four days later, directly after which a dose of ${ }^{14} \mathrm{C}$ leucine was administered. Twenty-four hours later a third laparotomy was performed in order to obtain material for examination.

In a further two control animals the ${ }^{14} \mathrm{C}$ leucine was given and the specimens were taken without any prior anaesthetics or laparotomies.

\section{Group 2}

In five baboons, auxiliary livers were inserted (Welch, 1955) and specimens were collected for baseline studies. The animals were not immunosuppressed. After four days, ${ }^{14} \mathrm{C}$ leucine was given and 24 hours later further specimens were obtained. Bile could not be obtained from the transplanted livers, however, as the gallbladder was always found to be empty, presumably because of the cholecyst-enterostomy which had been performed and because rejection had sharply reduced the output of bile.

\section{Group 3 (five baboons)}

The auxiliary livers were removed four days after insertion. ${ }^{14} \mathrm{C}$-leucine was then administered to the animals and the various parameters were measured in the remaining host livers 24 hours later.

PREPARATION AND CHARACTERIZATION OF THE ANTI-ALKALINE PHOSPHATASE ANTIBODY Highly purified alkaline phosphatase was prepared from rejecting baboon-liver allografts, using the method of Engstrom (1964). The final product, which contained 1 milligram of protein per millilitre, was mixed with an equal volume of Freund's complete adjuvant and each of five rabbits was immunized with $\mathbf{5 0 0}$ micrograms of protein, injected into multiple sites. The sera from four of these animals contained anti-alkaline phosphatase activity six weeks later, but were found also to react with multiple antigens on immunoelectrophoresis against baboon serum and extracts of baboon liver. After absorption with serum from a baboon with very low levels of alkaline phosphatase, the specificity of the rabbit antiserum was examined in the following ways: (a) By immunodiffusion and immunoelectrophoresis. (b) Increasing quantities of antiserum were added to liver extracts containing known amounts of alkaline phosphatase, glutamic-oxalacetic transaminase and lactic dehydrogenase and to solutions of ${ }^{125}$ I-labelled human albumin. Controls consisted of antiserum unabsorbed with baboon serum and 'normal' rabbit serum. After standing overnight at room temperature, the tubes were centrifuged and the residual activity in the supernatants was measured (table I). These tests were all performed in triplicate.

In the transplant experiments, liver extracts were prepared for testing by homogenizing $10 \mathrm{~g}$ of liver in a mixture of $30 \mathrm{ml}$ of $0.01 \mathrm{M}$ sodium acetate $-0.01 \mathrm{M}$ magnesium acetate and $17 \mathrm{ml}$ of $\mathrm{n}$-butanol and collecting the aqueous phase after centrifugation. Bile was diluted 1:20 with sodium acetate-magnesium acetate and serum was used neat. The $\mathrm{pH}$ of all the test solutions was adjusted to $7 \cdot 4$ before adding

\begin{tabular}{|c|c|c|c|c|c|c|c|c|c|c|c|c|c|}
\hline \multirow[t]{3}{*}{ Antigen (activity) } & & \multicolumn{8}{|c|}{ Rabbit Anti-alkaline Phosphatase Serum } & & & & \\
\hline & & \multicolumn{4}{|c|}{$\begin{array}{l}\text { Absorbed with Baboon } \\
\text { Serum }(m l)\end{array}$} & \multicolumn{4}{|c|}{ Untreated $(m l)$} & \multicolumn{4}{|c|}{ Normal Rabbit Serum $(\mathrm{ml})$} \\
\hline & & 0 & $0 \cdot 2$ & 0.4 & 0.8 & 0 & $0 \cdot 2$ & 0.4 & $0 \cdot 8$ & 0 & $0 \cdot 2$ & 0.4 & 0.8 \\
\hline Alkaline phosphatase (KAU \%) & $\begin{array}{l}\text { mean } \\
\pm \mathrm{SE}\end{array}$ & $\begin{array}{r}119 \\
2\end{array}$ & $\begin{array}{r}42 \\
2\end{array}$ & $\begin{array}{l}1 \\
1\end{array}$ & $\begin{array}{l}3 \\
1\end{array}$ & $\begin{array}{r}120 \\
2\end{array}$ & $\begin{array}{r}37 \\
3\end{array}$ & $\begin{array}{l}\mathbf{0} \\
\mathbf{0}\end{array}$ & $\begin{array}{l}0 \\
0\end{array}$ & $\begin{array}{r}116 \\
5\end{array}$ & $\begin{array}{r}118 \\
2\end{array}$ & $\begin{array}{r}109 \\
5\end{array}$ & $\begin{array}{r}124 \\
4\end{array}$ \\
\hline Lactic dehydrogenase & $\begin{array}{l}\text { mean } \\
\pm S E\end{array}$ & $\begin{array}{r}133 \\
7\end{array}$ & $\begin{array}{r}112 \\
5\end{array}$ & $\begin{array}{r}119 \\
7\end{array}$ & $\begin{array}{r}143 \\
4\end{array}$ & $\begin{array}{r}117 \\
2\end{array}$ & $\begin{array}{r}135 \\
4\end{array}$ & $\begin{array}{r}121 \\
4\end{array}$ & $\begin{array}{r}135 \\
5\end{array}$ & $\begin{array}{r}122 \\
6\end{array}$ & $\begin{array}{r}133 \\
5\end{array}$ & $\begin{array}{r}124 \\
8\end{array}$ & $\begin{array}{r}114 \\
8\end{array}$ \\
\hline Albumin $\left(\mathrm{C} / \mathrm{min} \times 10^{-3}\right)$ & $\begin{array}{c}\text { mean } \\
\pm S E\end{array}$ & $\begin{array}{r}342 \\
7\end{array}$ & $\begin{array}{r}375 \\
22\end{array}$ & $\begin{array}{r}370 \\
28\end{array}$ & $\begin{array}{r}406 \\
5\end{array}$ & $\begin{array}{r}358 \\
18\end{array}$ & $\begin{array}{r}246 \\
23\end{array}$ & $\begin{array}{r}216 \\
13\end{array}$ & $\begin{array}{r}227 \\
4\end{array}$ & $\begin{array}{r}386 \\
19\end{array}$ & $\begin{array}{r}349 \\
26\end{array}$ & $\begin{array}{r}349 \\
10\end{array}$ & $\begin{array}{r}402 \\
15\end{array}$ \\
\hline
\end{tabular}

Table I Reaction of rabbit antialkaline phosphatase serum with multiple antigens 


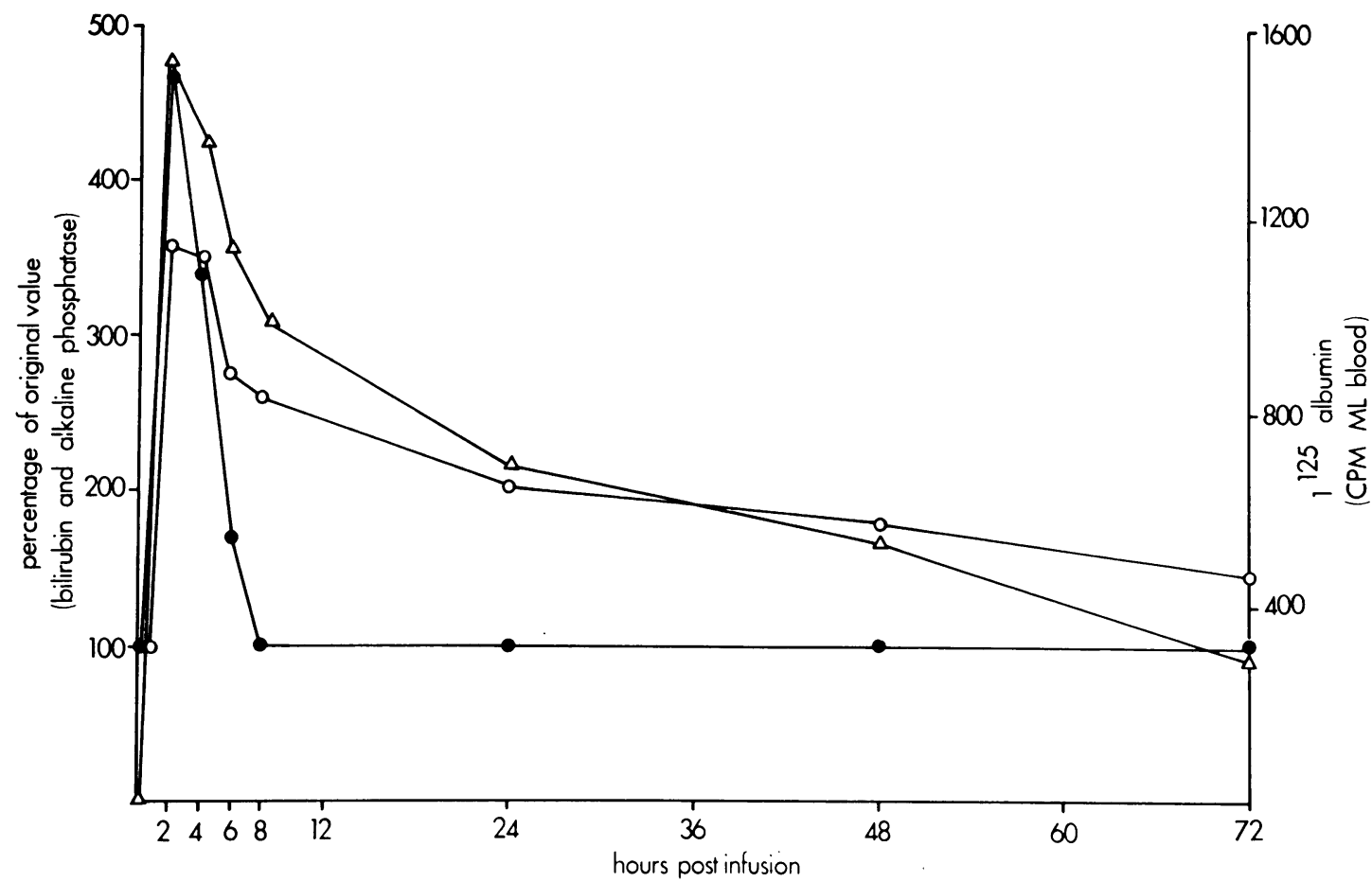

Fig 1 Disappearance-curves of bilirubin, alkaline phosphatase, and ${ }^{125}$ I-labelled albumin from the blood of a normal baboon after the intravenous injection of $5 \mu \mathrm{Ci}$ of ${ }^{125} \mathrm{I}$ albumin and $100 \mathrm{ml}$ of jaundiced serum containing $21 \mathrm{mg}$ bilirubin and $410^{2}$ King-Armstrong units of alkaline phosphatase. $-\longrightarrow=$ bilirubin; $\bigcirc-\bigcirc=$ alkaline phosphatase; $\triangle-\triangle={ }^{125}$ - labelled albumin

antiserum in optimal proportions. The mixtures were allowed to stand at room temperature for 24 hours and the precipitates were then collected on $0 \cdot 22 \mu$ millipore filters for counting in a Beckman scintillation counter.

\section{ENZYME ASSAYS AND HISTOLOGY}

Glutamic-oxaloacetic acid and pyruvic transaminases were measured by the method of Wrobleski, and alkaline phosphatase according to King and Armstrong. Histological sections were stained with haematoxylin and eosin.

\section{Results}

INFUSION EXPERIMENTS

Bilirubin was rapidly cleared from the serum, while the 125I-albumin levels slowly declined after equilibrating in the intra- and extravascular fluid compartments (fig 1). The pattern of disappearance of alkaline phosphatase resembled that of albumin, suggesting that it had entered the same 'pool' and was not accumulating in the liver or being excreted into the bile (or elsewhere). In support of this conclusion, no change occurred in the concentration of alkaline phosphatase in the liver or the bile (table II).

\begin{tabular}{|c|c|c|c|c|c|c|}
\hline \multirow{3}{*}{$\begin{array}{l}\text { Hours } \\
\text { after } \\
\text { Infusion }\end{array}$} & \multicolumn{6}{|c|}{ Alkaline Phosphatase Levels } \\
\hline & \multicolumn{3}{|c|}{$\begin{array}{l}\text { Liver } \\
(K-A \text { units/g) }\end{array}$} & \multicolumn{3}{|c|}{$\begin{array}{l}\text { Bile } \\
(K-A \text { units \%) }\end{array}$} \\
\hline & $I$ & $I I$ & $I I I$ & $I$ & $\boldsymbol{I I}$ & $I I I$ \\
\hline $\begin{array}{r}0 \\
8 \\
24 \\
48 \\
72\end{array}$ & $\begin{array}{l}4 \cdot 8 \\
4 \cdot 8 \\
4 \cdot 3 \\
4 \cdot 6 \\
4 \cdot 9\end{array}$ & $\begin{array}{l}3.7 \\
3.5 \\
3.8 \\
3.4 \\
3.6\end{array}$ & $\begin{array}{l}3 \cdot 1 \\
2 \cdot 9 \\
3 \cdot 7 \\
3 \cdot 6 \\
3 \cdot 2\end{array}$ & $\begin{array}{l}168 \\
142 \\
111 \\
124 \\
133\end{array}$ & $\begin{array}{r}116 \\
98 \\
134 \\
102 \\
108\end{array}$ & $\begin{array}{l}68 \\
71 \\
83 \\
59 \\
66\end{array}$ \\
\hline
\end{tabular}

Table II Sequential levels of alkaline phosphatase in the liver and bile of three baboons after an infusion of jaundiced serum ${ }^{1}$

${ }^{1}$ A sample of each bile specimen was weighed before and after evaporation and the alkaline phosphatase levels were adjusted to allow for variations in the concentration of the bile. The numerals I, II, and III refer to the baboons; the serum levels obtained in I are depicted in figure 1. 


\section{AUXILIARY LIVER TRANSPLANT EXPERIMENTS}

\section{Group 1}

Initial liver alkaline phosphatase activity in this group, as well as in groups 2 and 3 and in the infusion experiments, varied between 1.4 and 4.8 KingArmstrong units per gram liver.

The rate of incorporation of ${ }^{14} \mathrm{C}$-leucine into alkaline phosphatase was similar in all animals. None of the parameters was affected by the repeated anaesthetics and laparotomies. No radioactivity could be demonstrated in the alkaline phosphatase precipitated from the blood or bile.

The liver glutamic-oxaloacetic and pyruvic transaminases likewise remained fairly constant, varying between 84 and 110 and 47 and 78 units per gram liver respectively.

\section{Group 2}

The elevated serum transaminase levels which followed transplantation were accompanied by decreased concentration of the enzymes in the auxiliary graft, confirming the view that these enzymes 'leak out' of damaged cells. In contrast, the raised serum alkaline phosphatase was associated with enhanced activity in both host and transplanted livers as well as in the bile from the host livers (table III). This alkaline phosphatase was characteristic of the liver isoenzyme on kinetic studies (Hammond, Balinsky, Bersohn, and Jersky, 1973) and on starch-gel electrophoresis (fig 2). A four-fold increase in the incorporation of ${ }^{14} \mathrm{C}$-leucine into alkaline phosphatase was noted in both livers of each animal and significant counts appeared in the alkaline phosphatase in blood and in the bile from

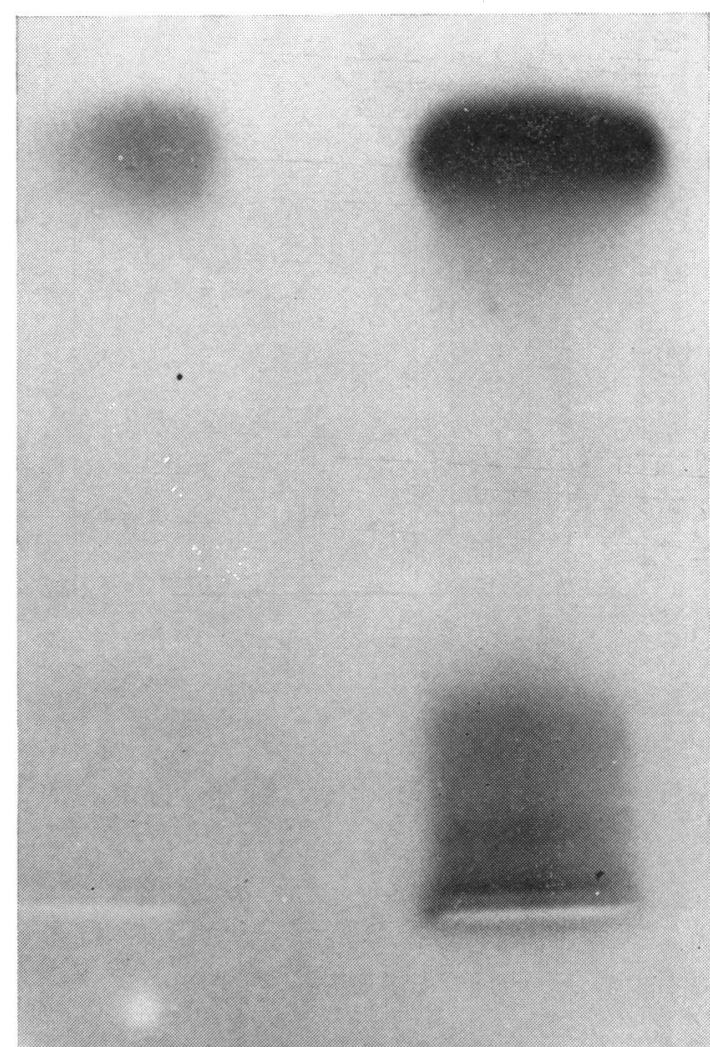

Fig 2 Starch-gel electrophoresis of serum alkaline phosphatase in a baboon before (left) and five days after auxiliary liver transplantation. The main band is in the $\beta$-globulin region and the fainter ones near the origin

\begin{tabular}{|c|c|c|c|c|c|c|c|c|c|}
\hline & \multirow[t]{3}{*}{$\begin{array}{l}\text { Experiment } \\
\text { Number }\end{array}$} & \multicolumn{2}{|l|}{ Serum } & \multicolumn{2}{|c|}{$\begin{array}{l}\text { Auxiliary Liver } \\
\text { Transplants }\end{array}$} & \multicolumn{2}{|c|}{ Host Livers } & \multicolumn{2}{|c|}{ Bile from Host Livers } \\
\hline & & \multicolumn{2}{|c|}{ Transplantation } & \multirow[b]{2}{*}{ Before } & \multirow[b]{2}{*}{ After } & \multirow[b]{2}{*}{ Before } & \multirow[b]{2}{*}{ After } & \multirow[b]{2}{*}{ Before } & \multirow[b]{2}{*}{ After } \\
\hline & & Before & After & & & & & & \\
\hline $\begin{array}{l}\text { Alkaline phosphatase }{ }^{1} \\
\text { (King-Armstrong units) }\end{array}$ & $\begin{array}{l}1 \\
2 \\
3 \\
4 \\
5 \\
\text { Mean }\end{array}$ & $\begin{array}{l}17 \cdot 6 \\
16.2 \\
10 \cdot 0 \\
11.6 \\
28.4 \\
16.8\end{array}$ & $\begin{array}{l}29 \cdot 8 \\
46 \cdot 0 \\
23 \cdot 1 \\
40 \cdot 0 \\
56 \cdot 8 \\
39 \cdot 1\end{array}$ & $\begin{array}{l}3.5 \\
3.1 \\
4.6 \\
3.8 \\
2.9 \\
3.6\end{array}$ & $\begin{array}{l}14 \cdot 1 \\
26 \cdot 0 \\
18 \cdot 3 \\
26 \cdot 6 \\
21 \cdot 4 \\
21 \cdot 3\end{array}$ & \begin{tabular}{l|}
$3 \cdot 2$ \\
$4 \cdot 7$ \\
$2 \cdot 8$ \\
$4 \cdot 3$ \\
$3 \cdot 4$ \\
$3 \cdot 7$
\end{tabular} & $\begin{array}{c}42 \cdot 7 \\
37 \cdot 4 \\
20 \cdot 9 \\
13 \cdot 7 \\
31 \cdot 3 \\
29 \cdot 2\end{array}$ & $\begin{array}{r}66 \\
120 \\
77 \\
152 \\
91 \\
101\end{array}$ & $\begin{array}{ll}1763 \\
1293 \\
987 \\
1216 \\
1032 \\
12258\end{array}$ \\
\hline $\begin{array}{l}\text { Glutamic pyruvate } \\
\text { transaminase } \\
\text { (Wroblewski units) }\end{array}$ & $\begin{array}{l}1 \\
2 \\
3 \\
4 \\
5\end{array}$ & $\begin{array}{l}12 \\
25 \\
27 \\
27 \\
21\end{array}$ & $\begin{array}{r}53 \\
33 \\
880 \\
76 \\
320\end{array}$ & $\begin{array}{l}51 \cdot 3 \\
46 \cdot 8 \\
47 \cdot 0 \\
67 \cdot 9 \\
71 \cdot 2\end{array}$ & $\begin{array}{r}22 \cdot 5 \\
25 \cdot 5 \\
2 \cdot 8 \\
19 \cdot 2 \\
42 \cdot 1\end{array}$ & $\begin{array}{l}50 \cdot 2 \\
78 \cdot 4 \\
49 \cdot 7 \\
60 \cdot 0 \\
58 \cdot 3\end{array}$ & $\begin{array}{l}61 \cdot 2 \\
76 \cdot 5 \\
41 \cdot 6 \\
51 \cdot 3 \\
57 \cdot 1\end{array}$ & \multicolumn{2}{|c|}{ Not done } \\
\hline
\end{tabular}

Table III Alkaline phosphatase and glutamic-pyruvic transaminase values before and five days following insertion of an auxiliary liver

${ }^{1}$ In serum and bile, the figures represent units $\%$ and in the livers, units per gram of liver. 


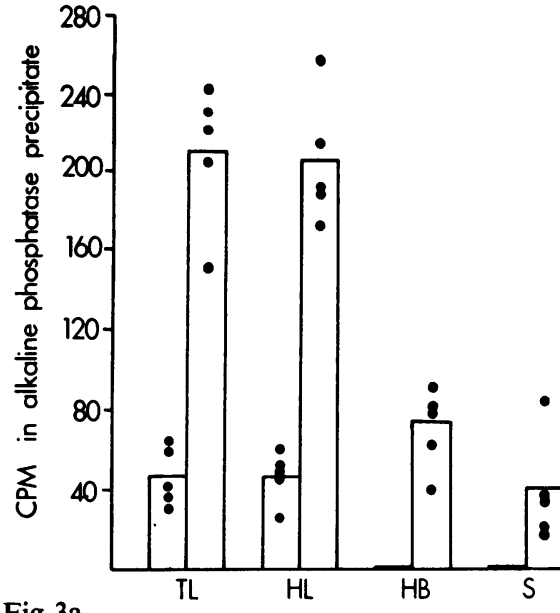

Fig 3a
Fig 3b

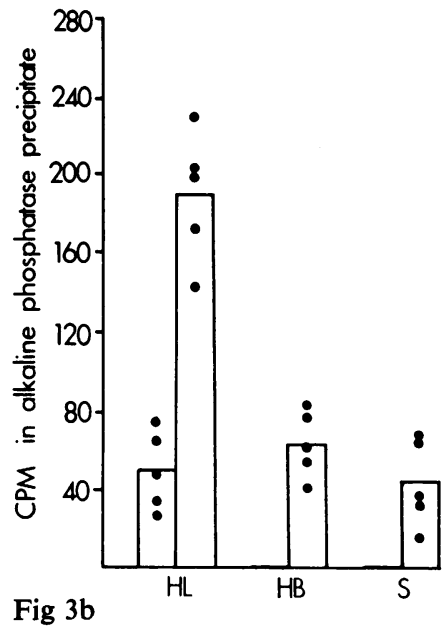

Fig 3 Incorporation of ${ }^{14} \mathrm{C}$ leucine into alkaline phosphatase in various tissues before and five days after auxiliary liver transplantation. In figure $3 a$ is depicted the results obtained when the ${ }^{14} C$ leucine was injected with the auxiliary livers in situ; figure $3 b$ shows the findings in the host when the grafts had been removed 24 hours previously. The results are expressed as counts per minute per $g$ liver tissue, per $\mathrm{ml}$ bile, and per $100 \mathrm{ml}$ serum. In each case the left of the two columns represents the pretransplant figures T.L. = auxiliary liver graft; H.L. = host liver; $\boldsymbol{H} . \boldsymbol{B} .=$ gallbladder bile from the host liver; $S=$ serum

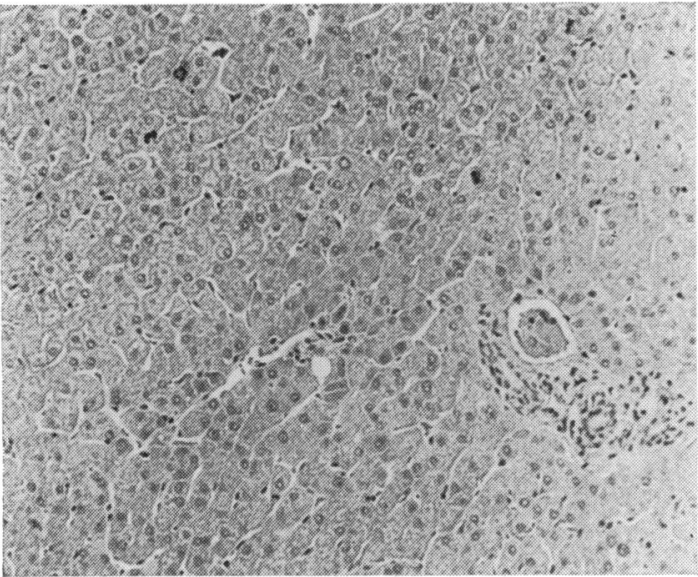

the host livers (fig 3a). Histologically, evidence of rejection was found in the grafts, while the host livers appeared normal (fig 4).

\section{Group 3}

The findings in the host livers after prior removal of the grafts were the same as those seen in the host livers in group 2 (fig $3 b$ ).

SPECIFICITY OF THE ANTI-ALKALINE PHOSPHATASE ANTIBODY

A single sharp precipitin line was obtained on immunodiffusion (fig 5). On immunoelectrophoresis, two precipitin lines were seen (fig 6).

Table I summarizes the results of the experiments in which the ability of the antisera to react with various antigens was tested. Both the absorbed and



Fig 4 The histological appearances of the host liver (left) and the auxiliary liver in the same animal, five days after insertion of the graft 


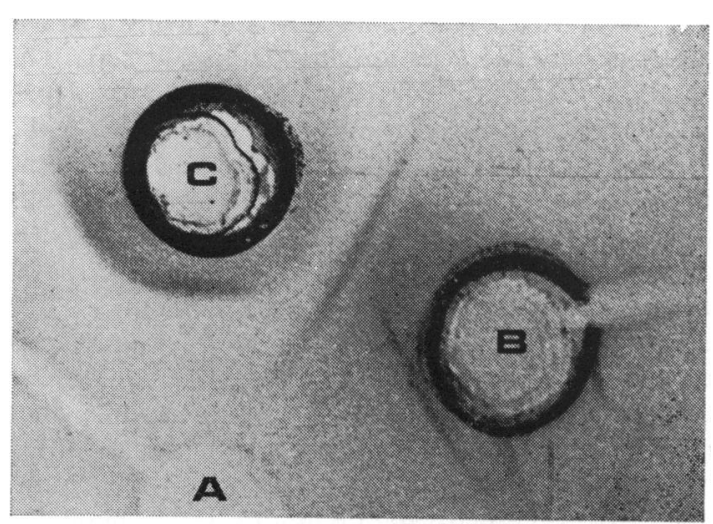

Fig 5 On immunodiffusion against a baboon-liver extract $(A)$ the unabsorbed rabbit anti-baboon-alkaline phosphatase serum $(C)$ yielded a broad band of precipitation. After absorption with baboon serum low in alkaline phosphatase, this antiserum $(B)$ now produced a single, sharp precipitin line. The line between $C$ and $B$ is the result of the reaction of the unabsorbed antiserum against the baboon serum in $B$

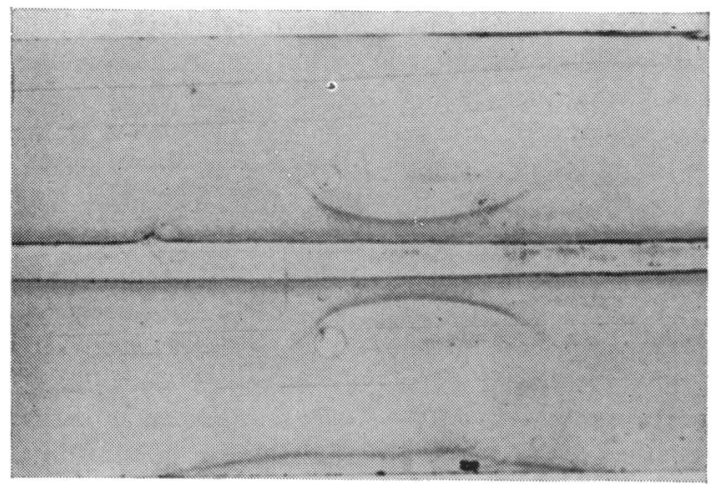

Fig 6 Immunoelectrophoresis. The wells contained an extract of baboon liver (see text) and the trough was filled with absorbed rabbit anti-baboon-alkaline-phosphatase serum. In addition to the dense precipitin line in the $\beta$-globulin region, a faint second precipitin line can just be made out

unabsorbed antisera were able to precipitate all of the alkaline phosphatase out of solution. However, while the unabsorbed antiserum also reacted with 125I-labelled albumin and with glutamic oxalacetic transaminase, the absorbed antiserum did not. Neither antiserum could be shown to react with lactic dehydrogenase. It is concluded from these experiments that the absorbed antiserum is largely, but not entirely, monospecific.

\section{Discussion}

It is now generally accepted that the alkaline phosphatase activity found in the liver probably arises in that organ and does not accumulate there from extrahepatic sites (Combes and Schenker, 1969). The results of kinetic studies on alkaline phosphatase extracted from normal and transplanted baboon livers (Hammond, Balinsky, Bersohn, and Jersky, 1973) and of electrophoresis of serum alkaline phosphatase in patients with liver disease (Newton, 1967) and in liver transplantation in baboons (fig 2) support this view. More direct proof is provided by the many experiments in which infused homologous alkaline phosphatase has failed to accumulate in the liver or be excreted in the bile (Cantarow and Miller, 1948; Wang and Grossman, 1949; Clubb, Neale, and Posen, 1965); similar results were obtained in the present experiments (table I, fig 1). Furthermore, it would be expected that if the alkaline phosphatase in hepatobiliary disease did originate outside the liver, insertion of an auxiliary liver should have no effect on serum levels of the enzyme, as excretion should proceed normally in the host's own liver. The fact that serum alkaline phosphatase rises after this procedure, even though biliary excretion not only does not diminish but actually increases (table II), strongly suggests that the increased enzyme activity arises in the host liver. As will be shown later, the increased alkaline phosphatase activity in these experiments is not confined to the host's liver but also occurs in the auxiliary liver.

Possible explanations for the increased hepatic alkaline phosphatase activity found in hepatobiliary diseases include an enhanced efficiency of the enzyme, release of enzyme from preformed inactive precursors, an increased rate of synthesis (or a diminished degradation in the face of a constant rate of production), and accumulation in the liver as a result of failure of biliary excretion.

Numerous workers have evaluated the possibility that the increase in alkaline phosphatase activity in hepatic biliary disease is due, not to any increase in the number of enzyme molecules, but to a change in the efficiency of action of the enzyme (Gutman, 1959). This could result from the release of activators or the removal of inhibitors, or from a conformational change in the enzyme molecule. The former possibility has been repeatedly excluded by comparing the enzyme activity in sera obtained before and after bile duct ligation with that found after mixing two samples. The enzyme activity of the mixture has always proved to be the mean of the activities of the unmixed samples, indicating that there has been no change in the concentration of 
modifying substances. However, increased efficiency could also result from conformational changes in the enzyme molecule, as has been shown to be the case in the steroid-mediated increase in alkaline phosphatase activity seen in cultured HeLa cells (Griffin and Cox, 1966). Mixing experiments would not differentiate between increased activity due to this mechanism and that resulting from an actual net increase in the amount of enzyme produced. Similarly, the experiments of Kaplan and Righetti (1970), in which it was shown that cyclohexamide could eliminate the increase in alkaline phosphatase activity which normally follows bile duct ligation in rats, do not exclude the possibility that protein synthesis is necessary for a conformational change in the enzyme molecule or for the release of enzyme from precursors. The fact that the steroid-mediated conformational change in HeLa cell alkaline phosphatase can be prevented by cyclohexamide provides a precedent for such an interpretation of their data.

In the present series of experiments, it has been shown that there is an increased rate of incorporation of ${ }^{14} \mathrm{C}$-leucine into alkaline phosphatase at the same time that alkaline phosphatase activity rises. This finding argues very strongly in favour of the hypothesis that the increased enzyme activity is due either to increased synthesis or diminished degradation of alkaline phosphatase, although two possible objections to this conclusion can be raised and should be considered. The first is that the accumulation of enzyme within the liver merely results from failure of biliary excretion. If this were so, an increase in the radioactive alkaline phosphatase per gram of liver would result even though there had been no true increase in the rate of production of the enzyme. That this is not the explanation is shown by the fact, discussed below, that increased intrahepatic incorporation of ${ }^{14} \mathrm{C}$-leucine into alkaline phosphatase can be demonstrated in the host livers, where normal quantities of enzyme-rich bile are being produced. The second and more serious objection concerns the specificity of the antigen-antibody reaction used to isolate the radioactive enzyme. It is likely that material other than antibody and alkaline phosphatase was present in the precipitate, even though this could not be demonstrated. However, although the imperfections of this method of isolating alkaline phosphatase are acknowledged, it is believed that valid conclusions can be drawn from these experiments for the reasons discussed previously. It is not possible, by the techniques used in these experiments, to distinguish between increased synthesis of alkaline phosphatase and diminished degradation.

The exact relationship between obstruction to bile flow and raised levels of hepatic alkaline phosphatase activity has been particularly controversial. The classical 'retention' theory, according to which alkaline phosphatase is normally cleared from the serum into the bile and accumulates when bile flow is obstructed, has been disproved by the findings that the isoenzyme in these conditions is of hepatic origin and that infused alkaline phosphatase is not excreted via the biliary tract. Nevertheless, the enzyme is normally present in bile in small quantities and large increases in activity occur in certain circumstances. Thus, ligation of one hepatic duct results in an increased amount of alkaline phosphatase in the bile of the unobstructed lobe (Polin, Spellberg, Teitelman, and Okumura, 1962). Similarly in the baboons which received auxiliary hepatic transplants, markedly enhanced alkaline phosphatase activity has been demonstrated in the bile from their own livers. Like the enzyme of non-hepatic origin, liver alkaline phosphatase is not cleared from the serum into bile (fig 1, table II), so that the high biliary levels in each of these experiments must have originated in the unobstructed lobe and the host's own liver respectively. This implies that in these situations the unobstructed liver tissue is also producing increased quantities of the enzyme which is then being excreted into the bile. Evidence that this is so is provided by the finding of an increased rate of incorporation of ${ }^{14} \mathrm{C}$-leucine into alkaline phosphatase in the host's liver even after removal of the auxiliary transplant, thus excluding the possibility that the labelled enzyme originated in the graft when both livers were in place. At the same time, there is a parallel increase in the quantity of radioactive alkaline phosphatase in the bile from the host's liver (fig 3b). It would therefore seem that in the absence of biliary obstruction, augmented hepatic production of alkaline phosphatase is accompanied by an increased excretion of the enzyme into bile. Presumably when obstruction is present, the alkaline phosphatase which would otherwise be lost in the bile, is retained and in this limited sense there appears to be some validity to a highly modified 'retention' theory.

The primary event, however, is an increase in the production of alkaline phosphatase by the liver. As a result of this, enzyme passes out of the cells into the blood and, if there is no biliary obstruction, into the bile. The passage of alkaline phosphatase into the blood is not dependent on biliary obstruction and can occur in its absence. Thus, after removal of an auxiliary transplant, injection of ${ }^{14} \mathrm{C}$-leucine into the baboon results in an increased production of the enzyme by the unobstructed host liver and this is accompanied by the appearance of radioactive alkaline phosphatase in the serum (fig $3 b$ ) even 
though there is no interference with biliary outflow. The basic cause of the hepatic overproduction of alkaline phosphatase is unknown. Biliary obstruction is clearly not essential; in the experimental situation described in the present paper the phenomenon was induced in apparently normal liver tissue. As there was no connexion between this liver and the graft other than via the bloodstream, it would appear that a humoral agent originating in the graft was responsible for 'switching on' the host liver. It is tempting to speculate that this hypothetical agent is a chemical which is normally produced in the liver and excreted into the bile at a rate near to the maximum possible. If that were the case, biliary obstruction would result in the retention of this substance and overproduction of the enzyme would ensue in both obstructed and unobstructed liver tissue. The fact that no overproduction of alkaline phosphatase occurred after infusion of jaundiced serum into normal baboons could be explained by postulating either that too small a dose was administered or that the substance is relatively unstable.

This work was carried out in the Michael and Janie Miller Laboratory. The biochemical tests were performed by $\operatorname{Dr} T$. Ipp of the South African Institute for Medical Research. The financial assistance of the Medical Research Council of South Africa is gratefully acknowledged.
References

Cantarow, A., and Miller, L. L. (1948). Nonexcretion of jaundiceserum alkaline phosphatase in bile of normal dogs. Amer. $J$. Physiol., 153, 444-446.

Clubb, J. S., Neale, F. C., and Posen, S. (1965). The behavior of infused placental alkaline phosphatase in human subjects. J. Lab. clin. Med., 66, 493-507.

Combes, B., and Schenker, S. (1969). In Diseases of the Liver, 3rd ed., edited by L. Schiff. Lippincott, Philadelphia and Toronto.

Engström, L. (1964). Studies on bovine liver alkaline phosphatase, purification, phosphate incorporation. Biochem. biophys. Acta (Amst.), 92, 71-78.

Griffin, M. J., and Cox, R. P. (1966). Studies on the mechanism of hormone induction of alkaline phosphatase in human cell cultures. II. Rate of enzyme synthesis and properties of base level and induced enzymes. Proc. nat. Acad. Sci. (Wash.), 56, 946-953.

Gutman, A. B. (1959). Serum alkaline phosphatase activity in diseases of the skeletal and hepatobiliary systems: a consideration of the current status. Amer. J. Med., 27, 875-901.

Hammond, K. D., Balinsky, D., Bersohn, I., and Jersky, J. (1973). Kinetic studies on alkaline phosphatase from baboon liver. Int. J. Biochem., 4, 511-520.

Kaplan, M. M., and Righetti, A. (1970). Induction of rat liver alkaline phosphatase: the mechanism of the serum elevation in bile duct obstruction. J. clin. Invest., 49, 508-516.

Myburgh, J. A., Abrahams, C., Mendelsohn, D., Mieny, C. J., and Bersohn, I. (1971). Cholestatic phenomenon in hepatic allograft rejection in the primate. Transplant Proc., 3, 501-504.

Polin, S. G., Spellberg, M. A., Teitelman, L., and Okumura, M. (1962). Origin of elevation of serum alkaline phosphatase in hepatic disease. Gastroenterology, 42, 431-438.

Wang, C. C., and Grossman, M. I. (1948). Nonexcretion of serum alkaline phosphatase by the liver and the pancreas of normal dogs. Amer. J. Physiol., 156, 256-260.

Welch, C. S. (1955). A note on transplantation of the whole liver in dogs. Transplant. Bull., 2, 54-55. 